\title{
Specify Other Muscle Relaxants Administered
}

National Cancer Institute

\section{Source}

National Cancer Institute. Specify Other Muscle Relaxants Administered. NCI Thesaurus.

Code C159296.

A request to specify muscle relaxants that were administered but not included on a list. 